\title{
LA CERÁMICA CONTEMPORÁNEA EN EL CUARTEL DEL CARMEN (SEVILLA)
}

\section{POST-MEDIEVAL POTTERY FROM CUARTEL DEL CARMEN (SEVILLA)}

\author{
por \\ ROSARIO HUARTE CAMBRA \\ PILAR SOMÉ MUÑOZ
}

\begin{abstract}
RESUMEN Este artículo pretende dar a conocer las producciones cerámicas contemporáneas realizadas en la ciudad de Sevilla. Para ello se han empleado los materiales hallados en la excavación del Cuartel del Carmen. Se han clasificado las lozas con una metodología sencilla basada principalmente en un criterio funcional.
\end{abstract}

\begin{abstract}
The present article try to release the contemporary pottery production in Seville city. In order to do the pottery classification, we use ceramics that come from Cuartel del Carmen (Quarter of Carmen) excavation. The archeological material was classified with a simple methodology base on a functional criterion approach.
\end{abstract}

En los últimos años, las numerosas excavaciones llevadas a cabo en el casco histórico de Sevilla han sacado a la luz restos de diversa naturaleza (arquitectónica, artística, cerámica, etc.) los cuales pertenecen a épocas relativamente recientes. Así pues, la Arqueología se ha adentrado, con una metodología propia fruto de las diversas experiencias, en el estudio de las épocas conocidas tradicionalmente como Historia Moderna e Historia Contemporánea. Estas aportaciones se van plasmando, en los últimos años, en una serie de publicaciones que dan a conocer los resultados obtenidos (por ejemplo Oliva y otros 1993a).

Sin embargo, hasta hace poco los materiales de época contemporánea no han sido considerados objetos de estudio arqueológico, siendo en la mayoría de las ocasiones desechados sin más. Ésta es una de las razones por la cual no abundan trabajos sobre las producciones cerámicas de este momento histórico. No debemos olvidar que la loza contemporánea es heredera de las tradiciones anteriores y puente hacia las producciones actuales, en las cuales se perciben similitudes muy notables. Con este artículo pretendemos otorgar la importancia que merecen estas variadísimas producciones y aportar una base para posteriores estudios. 
Los trabajos de investigación arqueológica llevados a cabo en el Cuartel del Carmen han facilitado el estudio de un conjunto de materiales pertenecientes a época contemporánea. La fecha fundacional del edificio se sitúa a mediados del siglo XIV (1358). Desde un primer momento se instala la Orden de los Carmelitas Descalzos, y durante cinco siglos el convento ve cómo su planta primitiva va evolucionando y ampliando sus dimensiones hasta ocupar el espacio que hoy día conocemos. Además de la Orden Carmelita, numerosas cofradías y hermandades tienen sus capillas dentro del edificio, por ejemplo La Soledad de San Lorenzo, las Siete Palabras o la Quinta Angustia. Con la invasión francesa a principios del siglo XIX la orden carmelita fue expulsada del convento y las tropas francesas tomaron el edificio expoliando sus riquezas. Después de la retirada de los franceses de España, los frailes carmelitas volvieron al Convento aunque por un período muy corto (1812-1835), ya que fueron exclaustrados definitivamente tras la desamortización de Mendizábal. Desde estos momentos el edificio es destinado a albergar al Regimiento de Infantería "Granada", siendo necesaria una adaptación de la planta conventual, adecuándola a las necesidades de su nueva función como cuartel tal y como se conoce en la actualidad. Así pues, a lo largo de su historia el edificio ha mantenido una constante ocupación hasta la segunda mitad del siglo XX, concretamente 1978, momento en que el ejército abandona el cuartel, entrando éste en una fase de deterioro lento, hasta que es destinado a sede del nuevo Conservatorio y Escuela de Arte Dramático de Sevilla, procediendo a su restauración y facilitando la entrada de un equipo interdisciplinar encargado de investigar la historia de esta construcción (Oliva y otros 1993b).

El edificio ha sido habitado ininterrumpidamente a lo largo de su historia, albergando además a dos colectivos importantes, aunque de distinta naturaleza: uno religioso y otro militar. Al ser grupos bastantes numerosos, el volumen de materiales cerámicos hallados también alcanza unas proporciones importantes, estando compuesto por colecciones cerámicas pertenecientes a diversos momentos históricos. La transformación del edificio conventual en edificio militar ha facilitado el hallazgo de materiales de época contemporánea. Los rellenos estudiados han aparecido en:

- Corte 59-A, situado en el ala oeste del claustro principal. Con un pavimento realizado a sardinel y con una pila ejerciendo la función de abrevadero, sería en época conventual un espacio destinado a animales. Tras la remodelación efectuada por los militares, a mediados del siglo XIX, la zona se cierra y compartimenta, habilitándose como cantina. El relleno cerámico corresponde a la unidad 2. 248, es de carácter detrítico, localizándose en un pozo.

- Corte 35-B. A inicios del siglo XVII la estancia 35 alberga la sacristía, decorada con un retablo y altar, además de tener hornacinas en las paredes donde se instalan una serie de armarios. A fines del siglo XIX se refuerzan los muros, no quedando restos de solería de este momento al ser sustituida por losa hidráulica a mitad del siglo XIX. El relleno estudiado pertenece a la unidad 271.

Para facilitar esta primera incursión en el conocimiento de las lozas de época contemporánea, hemos realizado una clasificación del material cerámico hallado en los rellenos del Cuartel del Carmen. La metodología empleada es sencilla; se ha procedido a dividir la cerámica en tres grandes grupos principales, basándonos en su funcionalidad dentro del ámbito doméstico, la vajilla de mesa que se emplea para la presentación y servicio de la comida, el menaje de cocina utilizado para la cocción y elaboración de los alimentos y otros usos domésticos, que engloba diversas piezas que se caracterizan por su multifuncionalidad o por no ajustarse su función a los otros dos grupos.

Dentro de estos apartados, a su vez, hemos diferenciado el material según la técnica de fabricación empleada: las realizadas en talleres alfareros, a torno y decoradas a mano se han denominado loza popular, y las elaboradas en fábricas, a máquina y decoradas con técnicas de estampación, reciben el nombre de loza industrial. 
En último lugar se ha clasificado el material desde un punto de vista estrictamente morfológico para empezar a dar cuerpo a una terminología cerámica.

\section{VAJILLA DE MESA}

Dividimos este apartado en dos producciones, bien diferenciadas entre sí: la loza popular, realizada en talleres artesanales, y la loza industrial, cuya elaboración se efectúa en grandes fábricas.

\section{a) Loza popular}

La cerámica popular presenta en Andalucía una gran riqueza que se refleja tanto en el elevado número de alfares existentes como en las diversas técnicas y producciones. En la ciudad de Sevilla el principal centro productor de este tipo de loza se localiza en Triana. Sus producciones cerámicas se caracterizan por poseer pastas de color amarillento y textura poco homogénea, con paredes de grosor medio y desgrasante fino, con una cubierta estannífera de tono generalmente blanquecino. Suelen presentar decoración pintada, empleándose en su ejecución diversas técnicas, entre ellas, a pincel, con muñequilla o con plantilla, apareciendo en ocasiones dos de estos métodos combinados en la misma pieza.

Los temas empleados son de muy diversa índole; se pueden apreciar motivos lineales, trenzados, vegetales y florales, destaca un motivo conocido como "puntilla de Berain" (fig. 1: 2) tomado de las producciones alcoreñas del siglo XVIII; la gama de colores empleada está constituida por el azul, el negro, el naranja, el verde y el amarillo, pudiendo aparecer combinados dos o más colores.

Las formas más frecuentes son:

- Platos de labio redondeado, paredes rectas divergentes con leve inflexión interna y base rehundida. Los motivos decorativos se disponen en el fondo y en la cara interna de la pared formando una guirnalda (figs. 1 y 2). Uno de los ejemplares de plato, concretamente el $\mathrm{n}^{\circ} 1$ de la figura 1 , podría tener una cronología ligeramente anterior (fines del siglo XVIII). Se puede observar la pervivencia del ala y caveto, aún bien diferenciados y la base va perdiendo el repié anular de momentos anteriores para dar lugar a la base rehundida de los demás ejemplares. Presenta una decoración de motivos de influencia oriental en color azul sobre un esmalte blanco.

- Fuentes hondas de borde engrosado, en ocasiones moldurado, paredes rectas divergentes y base rehundida. Tanto los motivos como las técnicas de decoración son similares a los de la forma anterior. Este tipo de pieza lo encontramos también con sólo una cubierta de engobe (fig. 3).

- Tazones o cuencos de labio redondeado, paredes curvas y pie anular, también con baño de esmalte sobre el que se dispone una decoración similar a la de las formas anteriormente citadas, aunque hay que señalar la aparición en una de las piezas de alternancia de decoración bícroma en su cara interna y polícroma en la externa (fig. 3).

- Lebrillos de pequeño tamaño con borde engrosado al exterior de sección cuadrada, paredes rectas divergentes y base plana. Aparecen con decoración polícroma vegetal o bien con bandas y trenzas de color verde sobre fondo blanco. Estos últimos se encuentran en gran cantidad, destacando la aparición de marcas realizadas sobre la pieza por los usuarios para distinguirlas en el manejo diario (fig. 4).

La vajilla de mesa se completa con una serie de producciones realizadas, durante el siglo XIX, en otros centros alfareros peninsulares como Manises y Salvatierra de los Barros. 
La loza popular valenciana adquiere una gran difusión exportándose a distintos puntos de la Península, aunque ahora su mercado se centre en las clases populares. Su fabricación no es exclusiva de los hornos de Manises, otros centros levantinos de la época son Onda y Ribesalbes; pero su fama determina el que se dé el nombre de loza de Manises a casi todas las producciones valencianas (Martínez 1987). El barniz estannífero es blanco brillante y los colores son más fuertes y presentan una gama más amplia; se hace un rojo llamado rojet de Onda, y un azul intenso que se denomina de Chóvar, puesto que se obtiene de sus minas de cobalto; la decoración pictórica está en manos de mujeres y niños que siguen modelos trazados, inventan, o interpretan de forma ingenua lo que aprecian a su alrededor (Soler 1985). De entre estas creaciones eminentemente populares destacan las llamadas "vajillas idílicas" (González 1962), este tipo se denomina así por los temas decorativos que presentan, todos ellos de inspiración naturalista. Así pues se aprecian figuras humanas (pareja de novios) que frecuentemente tienen sus extremidades rematadas por motivos vegetales. Entre los temas faunísticos se emplea el pájaro aislado en el centro y rodeado de ornamentación vegetal. Otras veces es sustituido por un fruto o temas florales diversos. Los fragmentos hallados en el Cuartel del Carmen se caracterizan por tener unas pastas de tono rosado propio de la zona levantina, de textura compacta, con unos desgrasantes finos y paredes de grosor medio. Aparecen cubiertos con un esmalte brillante de color blanco lechoso de buena calidad, sobre el cual se pinta con colores azules, naranjas, negros, verdes y amarillos. Los temas decorativos son variados, aunque abundan los de carácter floral y vegetal; encontramos además otro de los motivos decorativos característico de las producciones de Manises, concretamente el "kiosco", representación de un pabellón de estilo chinesco cuyo dibujo se repite principalmente en los platos del siglo XIX (Soler 1985). La única forma reconocible que poseemos es el plato con ala cóncava que puede presentarse con fondo plano o con pie anular (fig. 5). Podemos pensar por las características de estilo de estas piezas que pudieron ser empleadas tanto para el servicio de mesa, como con un carácter meramente ornamental.

También están presentes producciones de otros centros alfareros como Salvatierra de los Barros, de donde procede una base de forma cerrada y pasta rojiza que presenta una decoración, consistente en roleos y palmetas, bruñida sobre la pieza (fig. 5).

\section{b) Loza industrial}

Consideramos como loza industrial aquellas producciones realizadas con técnicas industriales; de ellas sólo están presentes en el yacimiento las correspondientes a las fábricas de Pickman y Sargadelos.

En 1841 se funda la fábrica de cerámicas de La Cartuja de Sevilla para competir con las lozas inglesas que dominaban un sector del mercado. Se caracterizan básicamente por unas pastas blancas, debidas al empleo de caolín, y por utilizar un sistema de decoración consistente en la estampación de los motivos bajo una cubierta de vedrío transparente. El procedimiento de estampar la loza se llevó a cabo por primera vez en Inglaterra a mediados del siglo XVIII; consiste en grabar el motivo en una plancha de cobre, la cual una vez tintada se impresiona sobre un papel fino, que a su vez se aplica a la pieza bizcochada que absorbe el color; finalmente se da a la pieza una cubierta de vedrío transparente y pasa al horno para la última cocción. El proceso de moldeado consta de dos técnicas; en el caso de los platos y piezas planas se moldea directamente a máquina, mientras que para la realización de piezas huecas se emplean moldes de escayola donde se vierte pasta líquida, la cual se solidifica dando lugar a la forma deseada. En ambos casos, una vez moldeadas las piezas, se repasan y pulen. 
Los fragmentos aparecidos en el Cuartel del Carmen son relativamente escasos, no pudiendo ser datados con seguridad ya que los sellos de fábrica, en caso de aparecer, no están completos y la mayoría de las series decorativas se repiten hasta hoy día de manera constante.

Están presentes tanto "lozas blancas" sin decorar, como estampadas. Las formas más habituales son platos con ala, tazas, cuencos, etc. con variedad de tamaños (fig. 6).

Los motivos decorativos, copiados en gran parte de los creados por los ingleses, o al menos inspirados en ellos, junto con los colores son los tradicionales que aún hoy encontramos, guirnaldas de motivos geométricos y florales junto a paisajes reales o fantásticos, en colores azul, negro, verde, marrón y rosa. Además aparecen otros motivos menos frecuentes a base de bandas o líneas en tonos naranja y amarillo.

Merecen mención aparte las producciones de encargo realizadas para el cuartel. Éstas están decoradas con motivos heráldicos que aluden al regimiento alojado en el edificio; también están presentes motivos epigráficos referentes a usos concretos a los que estarían destinadas las piezas, como pueden ser comedor de sargentos o comedor de tropa (fig. 7).

Perteneciente a la fábrica de loza de Sargadelos sólo constatamos un ejemplar fragmentado de plato con ala, decorado en el fondo, en color verde, mostrando un paisaje idílico con un gran jarrón en primer término. En el ala se dispone una guirnalda de flores y pequeños jarrones.

\section{MENAJE DE COCINA}

Dentro del ámbito del menaje de cocina podemos distinguir dos grupos. Por un lado los recipientes empleados en la cocción de alimentos y por otro los que sirven para guardar los comestibles. Las piezas destinadas al fuego presentan como características generales unas pastas rojizas y poco compactas, con desgrasantes gruesos, de paredes medias y con una cubierta de vedrío plumbífero melado que se aplica en el interior, chorreando en ocasiones por el exterior, y cuya función es la de impermeabilizar la pieza.

Las formas habituales son ollas y cazuelas (fig. 8). Hay que señalar la pervivencia de las características formales de esta vajilla debido a su funcionalidad, aunque en menor proporción que en momentos anteriores, ya que van siendo sustituidas progresivamente por utensilios elaborados con otros materiales, fundamentalmente metales.

Las ollas poseen un cuello corto cilíndrico, panza globular, base convexa y dos asas; las cazuelas en líneas generales poseen un borde engrosado al exterior, algunos con moldura para encajar una tapadera, paredes divergentes y base convexa, en ocasiones presentan dos asas horizontales debajo del borde.

Para el almacenamiento de productos se utilizan formas ya conocidas, como la orza (fig. 9), que se caracteriza por un borde de sección triangular, paredes curvas convergentes, base plana y dos asas, cubierta de un esmalte verde, además de jarros y jarras de diverso tamaño que también pueden presentar este tratamiento. Formalmente presentan cuello cilíndrico, cuerpo de tendencia globular y base plana o con pie anular, diferenciándose según el número de asas que presenten; así el jarro tiene solamente un asa y la jarra dos o más.

Otra de las formas usadas es el bote de cuerpo cilíndrico y base plana, que aparece decorado con bandas verdes y cadenetas negras sobre fondo blanco. Encontramos fragmentos de gres, generalmente pertenecientes a botellas destinadas a la contención de líquidos. 


\section{OTROS USOS DOMÉSTICOS}

Incluimos en este apartado una serie de piezas que manteniendo un claro uso doméstico se caracterizan por su multifuncionalidad. Todas las piezas registradas pertenecen a talleres trianeros y participan de sus características formales y estéticas.

Así pues contamos con el lebrillo, el cual podía utilizarse en la cocina para la preparación y almacenamiento de alimentos, aunque también estaba destinado a la higiene personal y comunitaria (lavado de ropa y utensilios). Tipológicamente mantiene su forma habitual, borde engrosado, paredes rectas divergentes y base plana, variando en su decoración. Además de las tradicionales piezas meladas, encontramos piezas polícromas pintadas en colores verde, azul, amarillo y negro con motivos geométricos, florales y zoomorfos; también aparecen decoradas con la técnica de estampación mediante plantilla, presentando un motivo de carácter costumbrista (figs. 11 y 12). Debemos mencionar también unos lebrillos de gran tamaño, cubiertos de vedrío melado en el interior, con un orificio en la base para el desagüe, lo cual nos indica un uso específicamente higiénico.

Los bacines mantienen en general su forma anterior, base plana, paredes divergentes, cuerpo troncocónico y borde con ala, aunque desaparecen las asas y su tamaño es mayor. Se decoran en su superficie externa a base de líneas, bandas, cadenetas y motivos figurativos, en color amarillo, azul, verde y negro, y suelen presentar en el borde comas azules (figs. 10 y 11).

Deagan, en su estudio sobre los hallazgos cerámicos de los yacimientos coloniales en América, señala la aparición de un tipo cerámico al que denomina "Blue-Green Basin", el cual presenta pastas de tono beige y consistencia muy homogénea, con un esmalte blanco en el que se dispone una decoración en tonos azul oscuro, verde y negro, generalmente ornamentando bacines y lebrillos. Cronológicamente sitúa este tipo en las primeras décadas del siglo XIX; la misma autora señala en los estudios de Goggin un tipo llamado "Triana Polícromo" y "Triana Simple" en función de su decoración (Deagan 1987).

\section{CONSIDERACIONES FINALES}

Para finalizar esta presentación de los materiales cerámicos del Cuartel del Carmen, haremos unas breves reflexiones.

En el conjunto de los materiales, podemos observar un gran volumen de vajilla de mesa, principalmente platos y fuentes hondas, todos ellos decorados, la inmensa mayoría procedentes de los alfares de loza popular emplazados en Triana. En menor cantidad encontramos loza industrial, principalmente de la fábrica de Pickman, y loza popular cuyo origen se sitúa en Manises. Complementando la colección cerámica perteneciente a este momento tenemos otras producciones trianeras, como son los lebrillos y los bacines.

Debido a la gran profusión de la vajilla de mesa de carácter popular podríamos decir que ésta era usada en el vivir diario del cuartel, principalmente por el conjunto de la tropa, hecho que se corrobora con el siguiente ejemplo: se han encontrado en gran cantidad unos lebrillos de pequeño tamaño, decorados con bandas y una trenza en color verde sobre un fondo blanco, que presentan una amplia gama de marcas, principalmente de aspecto geométrico (cruces, cuadrados, líneas, etc.) que señalarían el uso de un único propietario. Por otro lado la vajilla de mesa de tipo industrial es más escasa, por ser en sus primeros momentos un artículo de lujo. No obstante a medida que el siglo transcurre las producciones se intensifican, debido a los encargos del propio cuartel, al pedir a la fábrica Pickman vajillas destinadas a un uso específico (comedor, hospital) o simplemente decoradas con el escudo del 
regimiento. Su uso estaría restringido a los altos mandos y quizás al cuerpo de oficiales y a la tropa en ocasiones especiales, pues uno de los anagramas registrados se refiere al comedor de tropa.

Del resto del ajuar doméstico, es decir el menaje de cocina (cazuelas y ollas) y otros usos (lebrillos y bacines), es lógico suponer que se emplearían de manera indistinta por todos los habitantes del cuartel.

Cronológicamente es complicado establecer unos límites que nos enmarquen estas cerámicas. La loza popular pervive con sus características morfológicas y estilísticas, es decir, se mantiene su repertorio de formas y se siguen decorando con las mismas técnicas y motivos; incluso hoy día, el mercado ofrece producciones de esta clase. La loza industrial fabricada en Pickman sufre un proceso similar, es decir, se repiten muchos de sus modelos apenas sin variaciones importantes hasta nuestros días.

Es probable que las producciones sevillanas de loza popular se inicien a partir del siglo XVIII manteniendo sus características durante el siglo XIX. Sin embargo, a través de los datos cronológicos aportados por la excavación todo el material presentado en este estudio se podría encuadrar durante todo el siglo XIX, concretamente desde 1835 , fecha de la expulsión definitiva de los religiosos e inicio de las remodelaciones militares, dato reafirmado también por la incorporación de las lozas industriales a partir de 1841, y principios del siglo XX.

Conviene puntualizar que a medida que avanza el siglo las producciones cerámicas van siendo sustituidas progresivamente por piezas fabricadas en otros materiales. Este seria el caso, por ejemplo, de la disminución constante de las tradicionales piezas utilizadas, en el menaje de cocina, para la cocción de alimentos por recipientes metálicos de mayor capacidad y resistencia; lo mismo ocurriría con otros objetos como platos, jarros, etc.

\section{BIBLIOGRAFÍA}

DEAGAN, K. (1987): Artifacts of the Spanish Colonies of Florida and the Caribbean, 1500-1800. Washington, Smithsonian Institution Press.

GONZÁLEZ, M. (1933): Cerámica española. Barcelona.

- (1962): "Cerámica popular valenciana. Vajillas idílicas", Anales del Centro de Cultura Valenciana. MARTÍNEZ, B. (1978): Cerámica española en el instituto Valencia de don Juan. Madrid.

OLIVA, D. y otros (1993a): Rehabilitación de la casa palacio Miguel de Mañara. Sevilla. (1993b): Intervención Histórico-Arqueológica en el Cuartel del Carmen. Sevilla 1990-1993. Sevilla.

SOLER, M. P. (1985): Museo Nacional de cerámica y artes suntuarias González Martí. Palacio de dos Aguas. Valencia. Madrid, Ministerio de Cultura. 

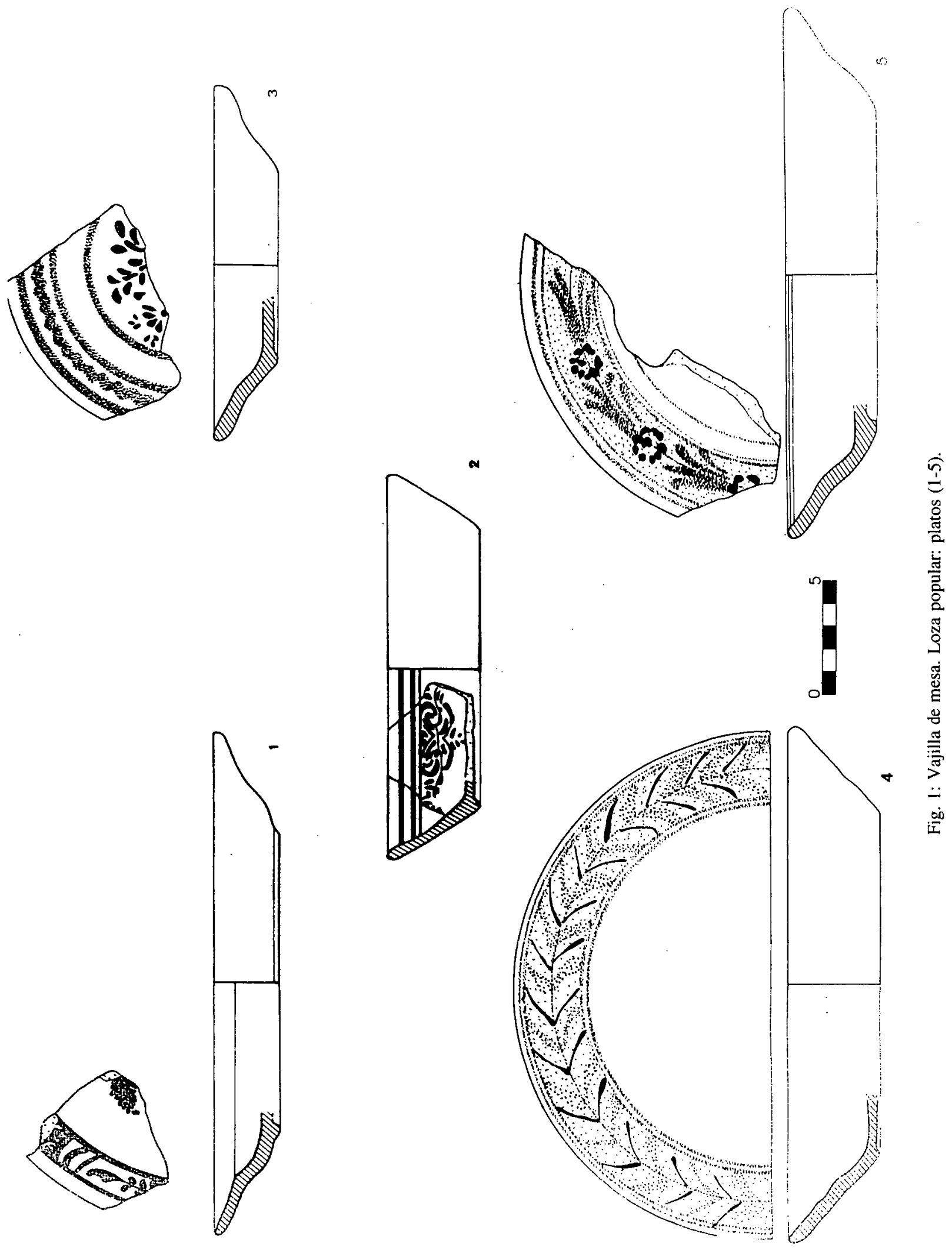

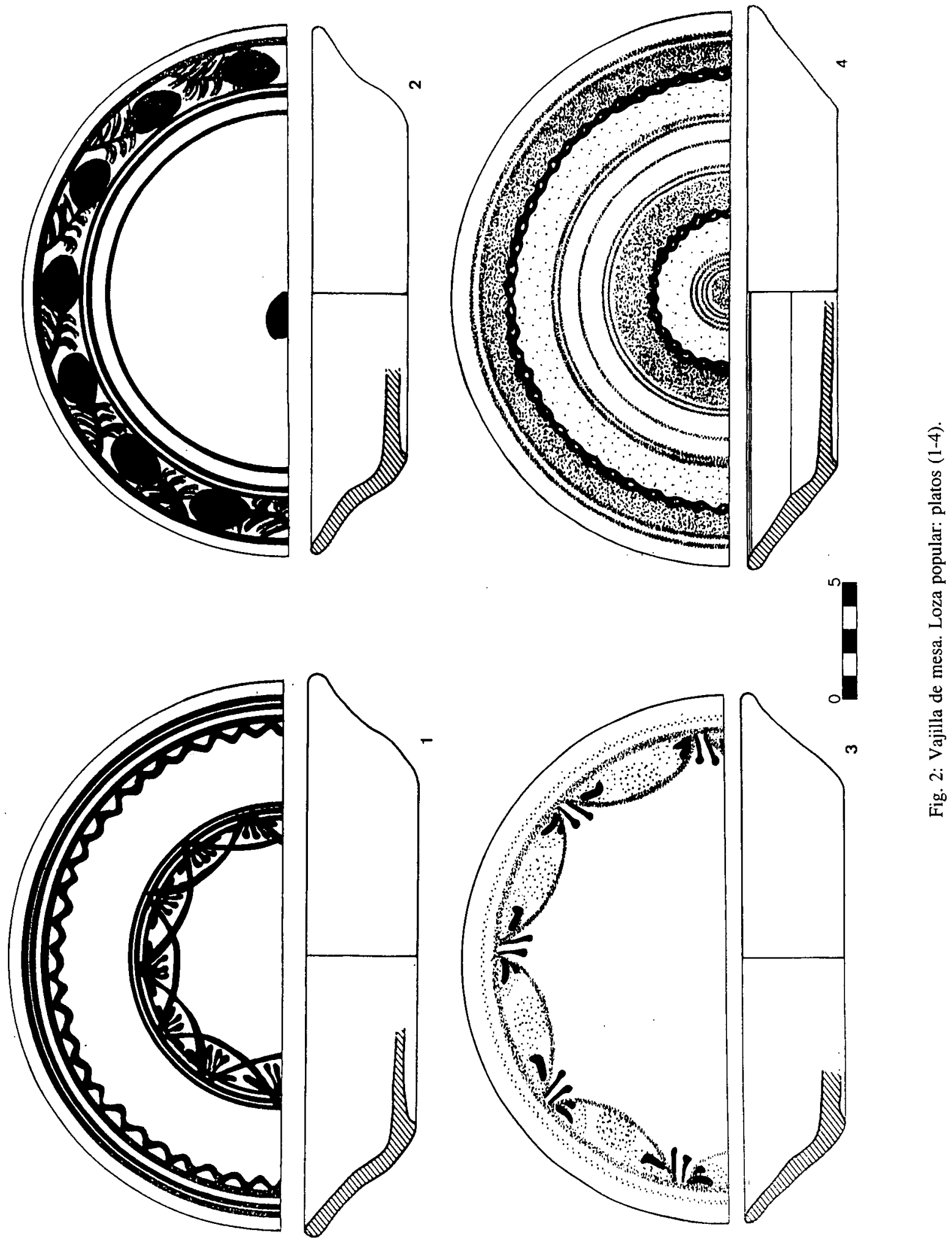

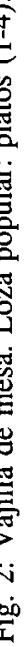



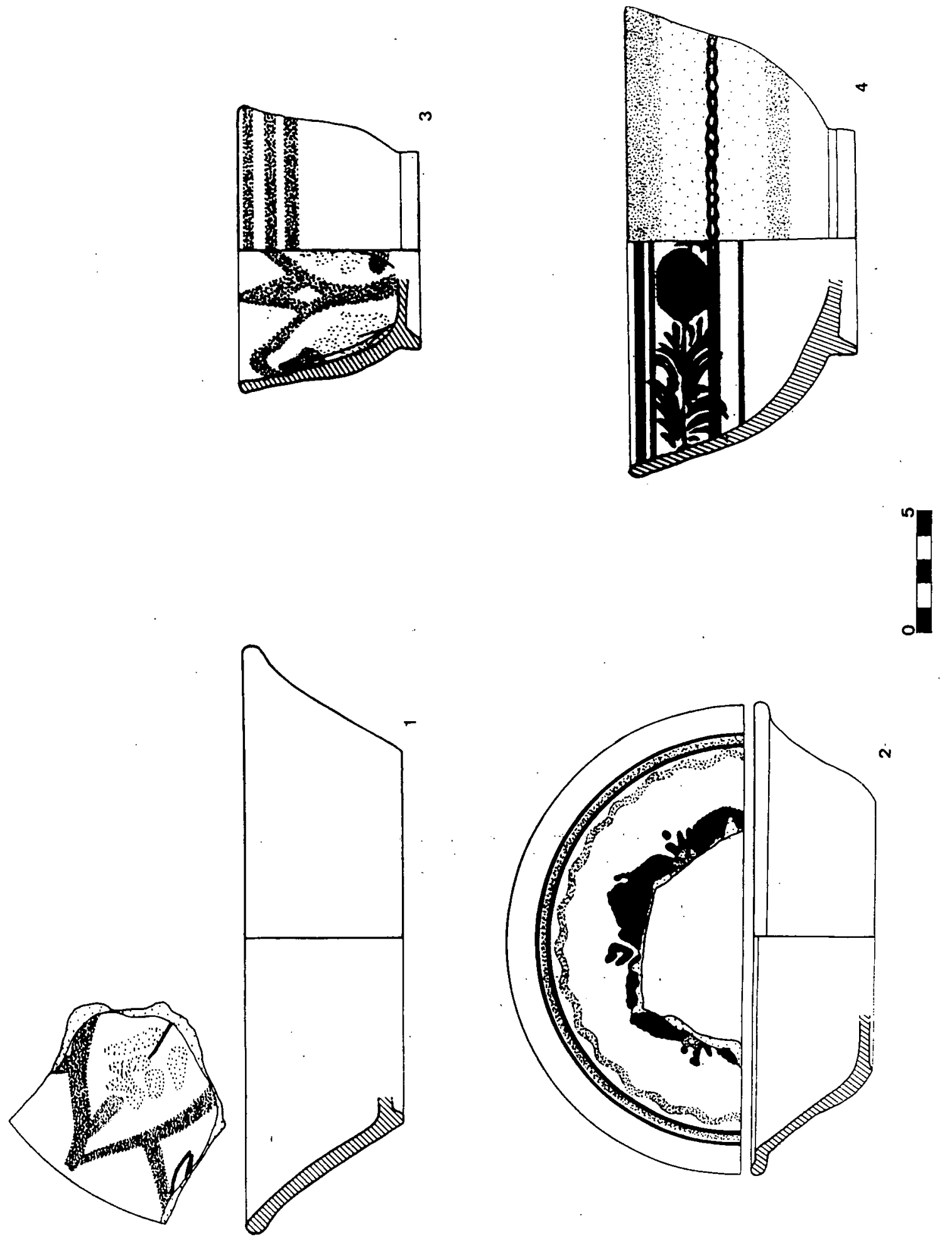

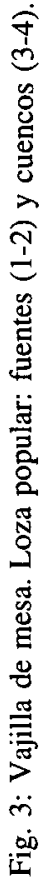



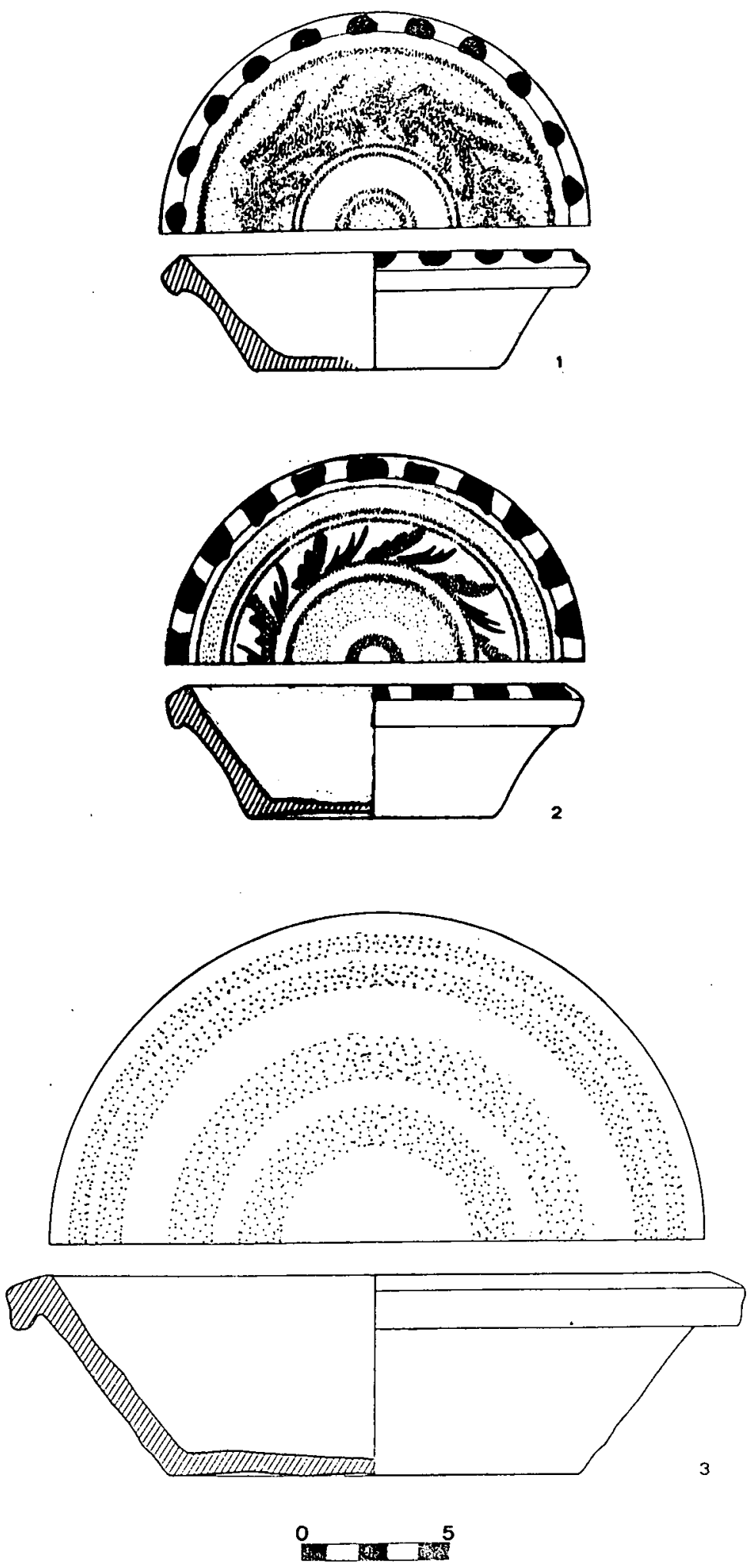

Fig. 4: Vajilla de mesa. Loza popular: lebrillos (1-3). 

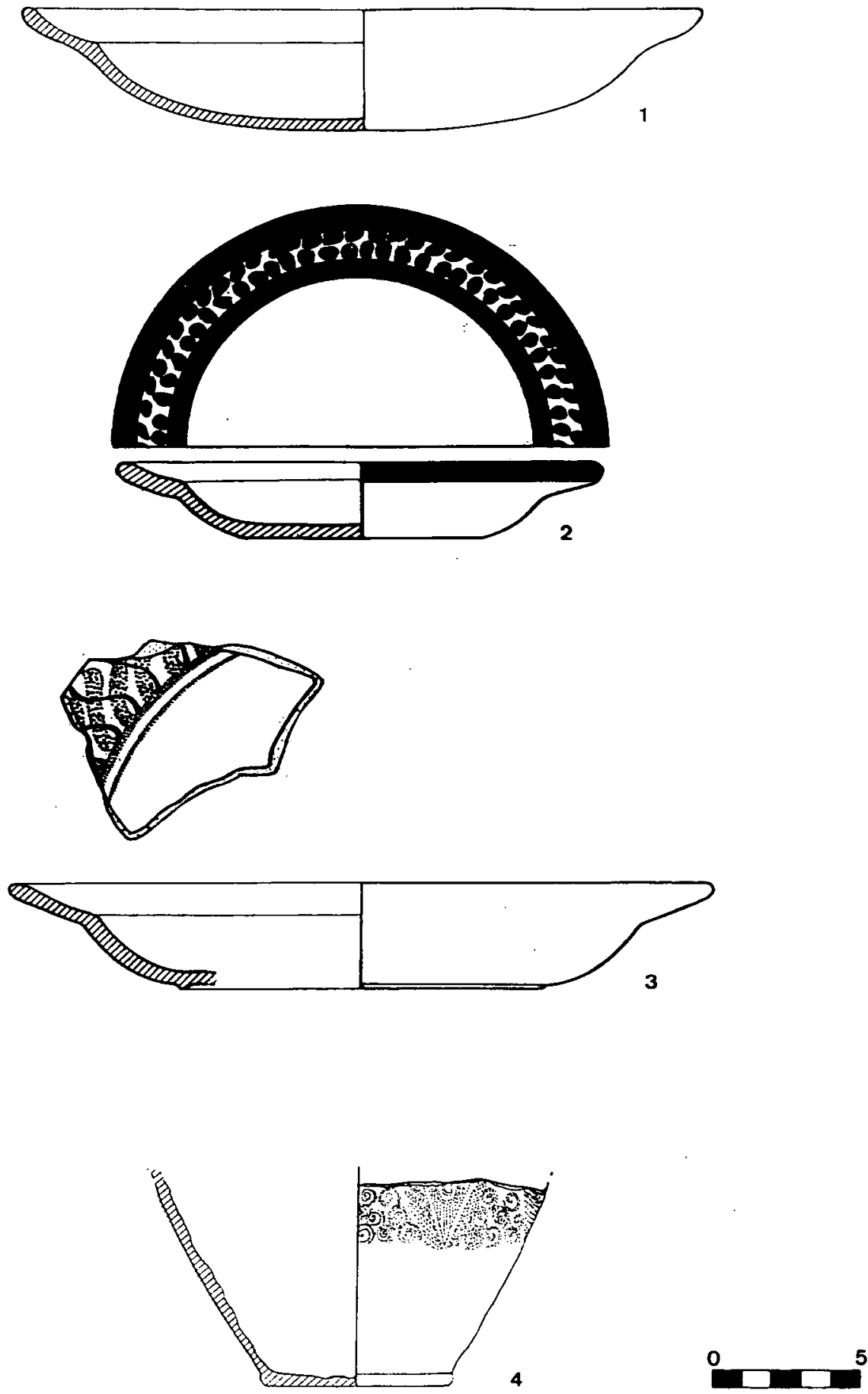

Fig. 5: Vajilla de mesa. Loza popular: platos de Manises (1- 3) y cerámica de Salvatierra (4). 

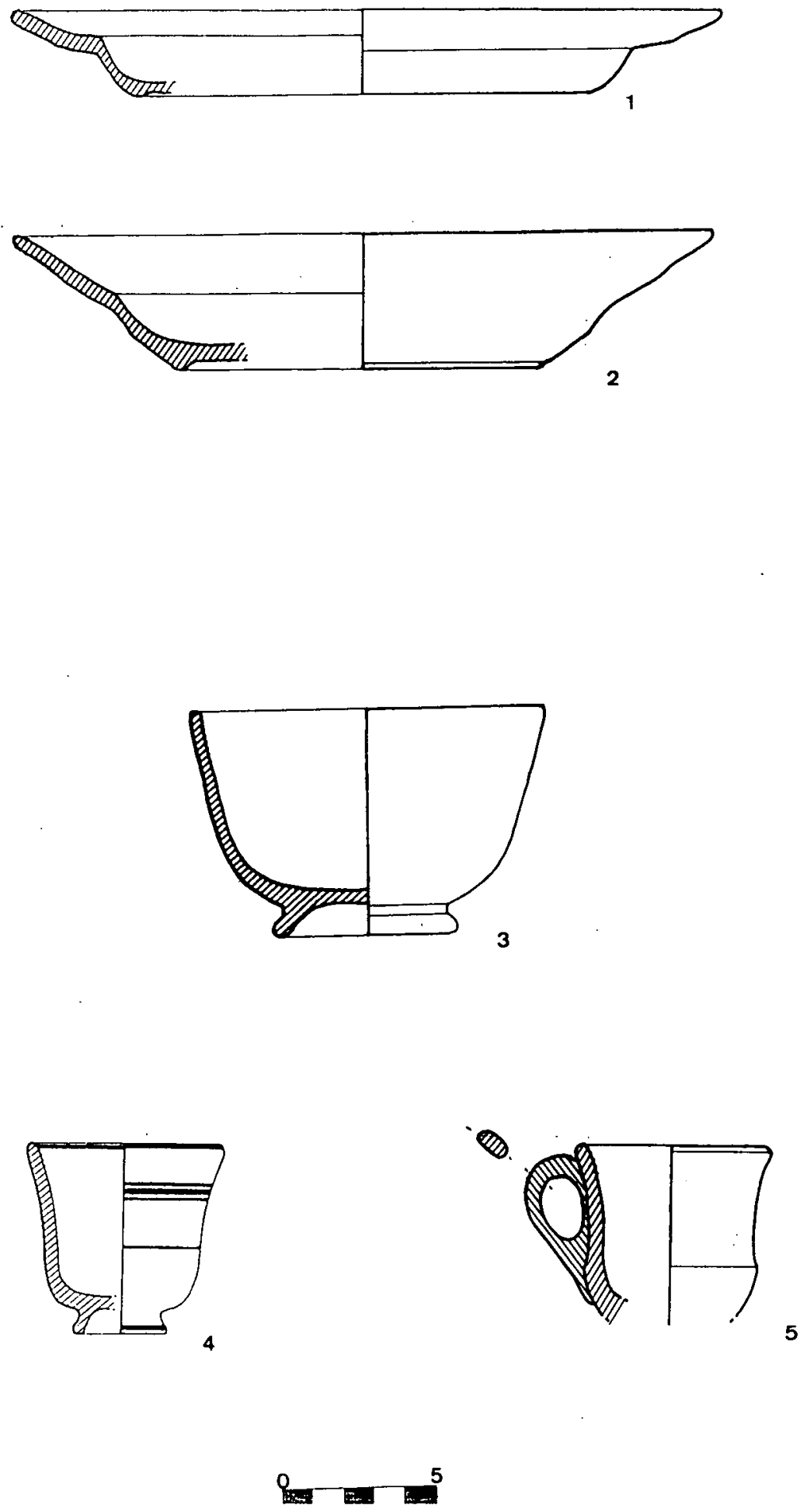

Fig. 6: Vajilla de mesa. Loza industrial: platos (1-2), cuenco (3) y tazas (4-5).

ISSN: 1133-4525 ISSN-e: 2255-3924

SPAL 4 (1995)

http://dx.doi.org/10.12795/spal.1995.i4.09 

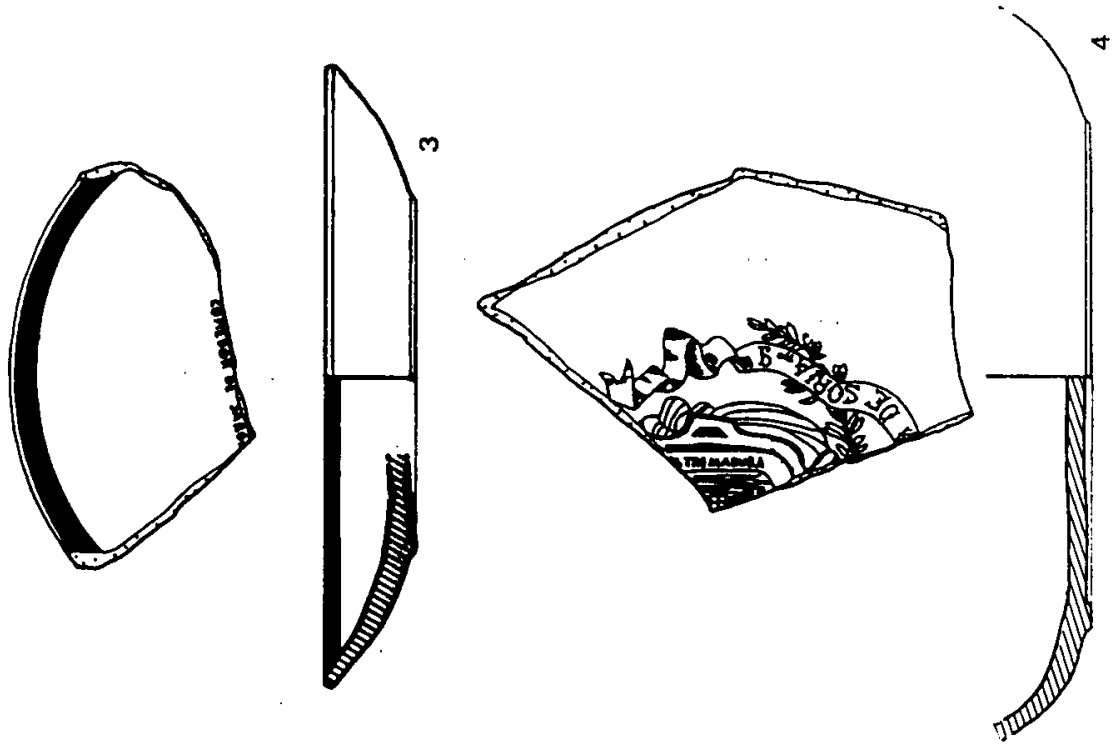

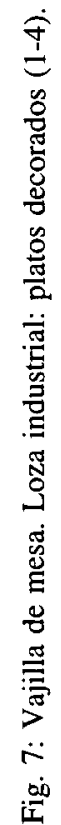
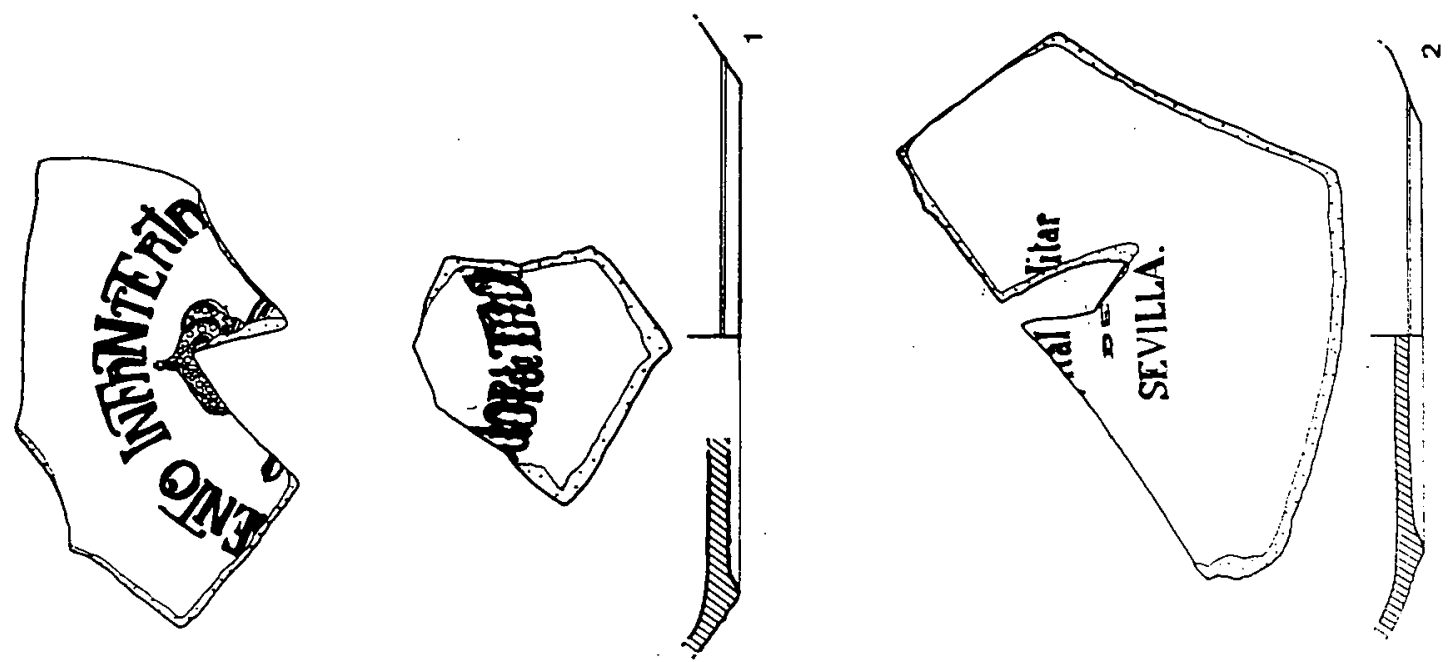

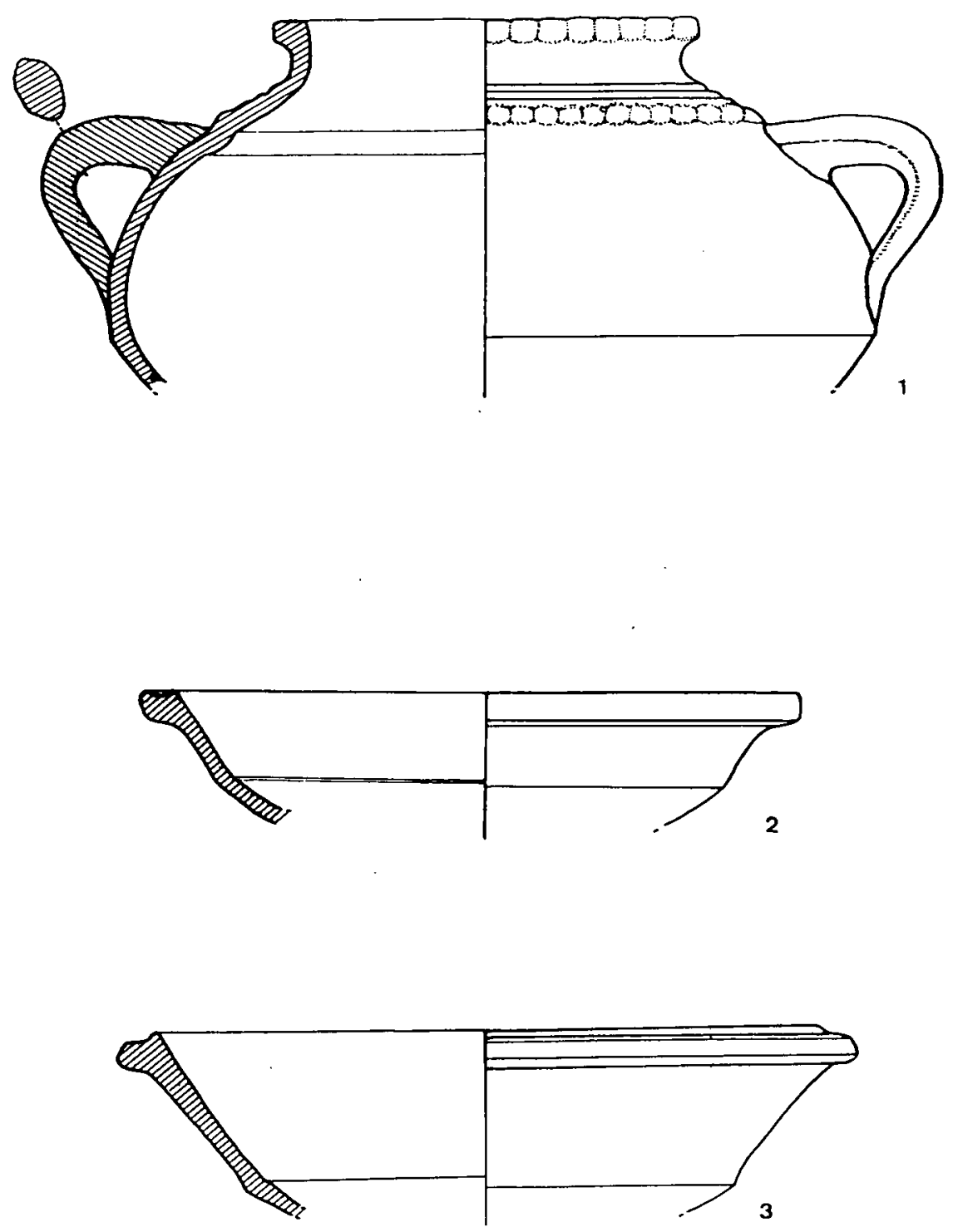

$\stackrel{0}{2}{ }^{5}$

Fig. 8: Menaje de cocina: olla (1) y cazuelas (2-3). 

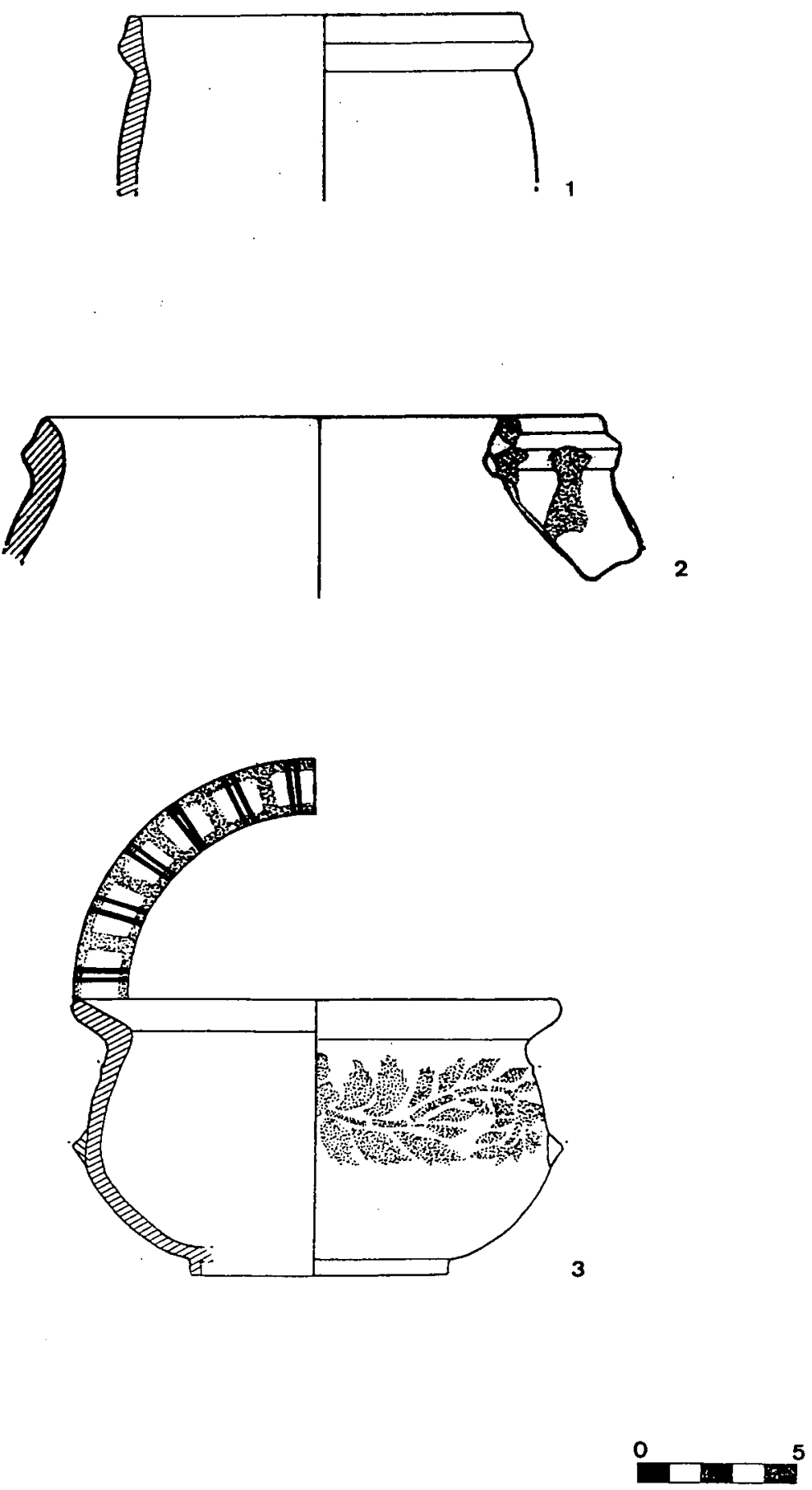

Fig. 9: Menaje de cocina: orzas (1-2), forma abierta (3). 

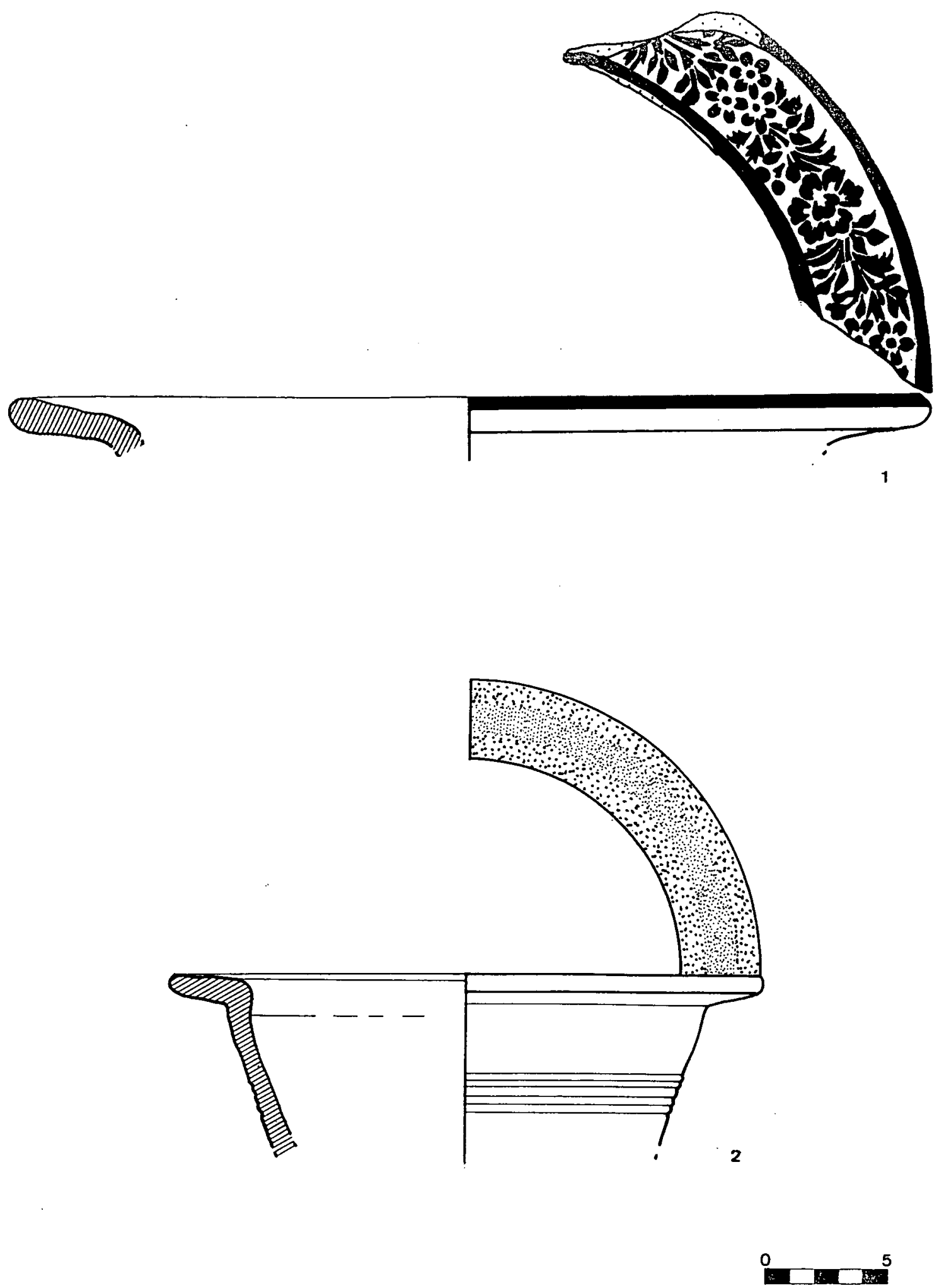

Fig. 10: Usos domésticos: bacines (1-2). 

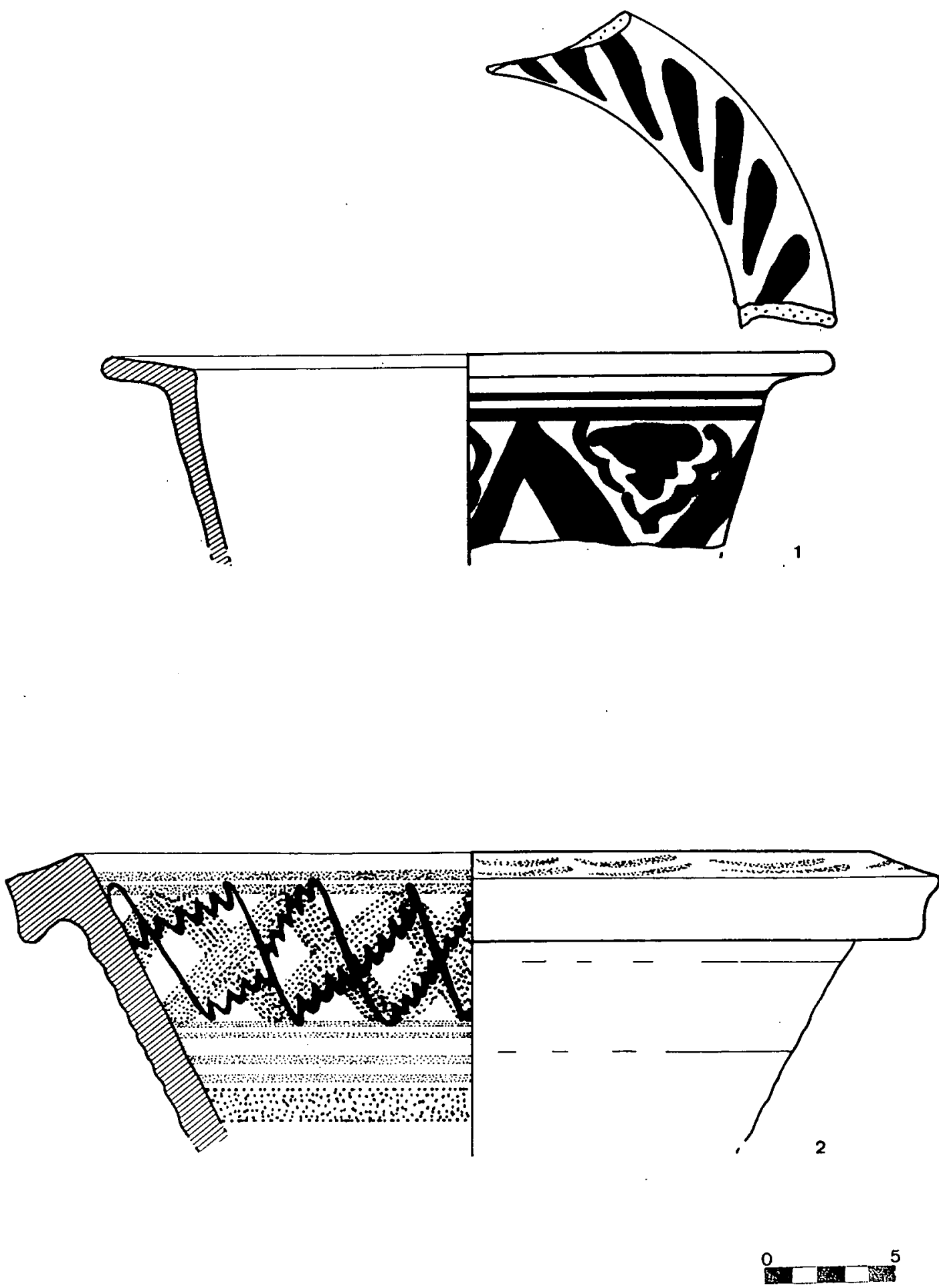

Fig. 11: Usos domésticos: bacín (1) y lebrillo (2). 

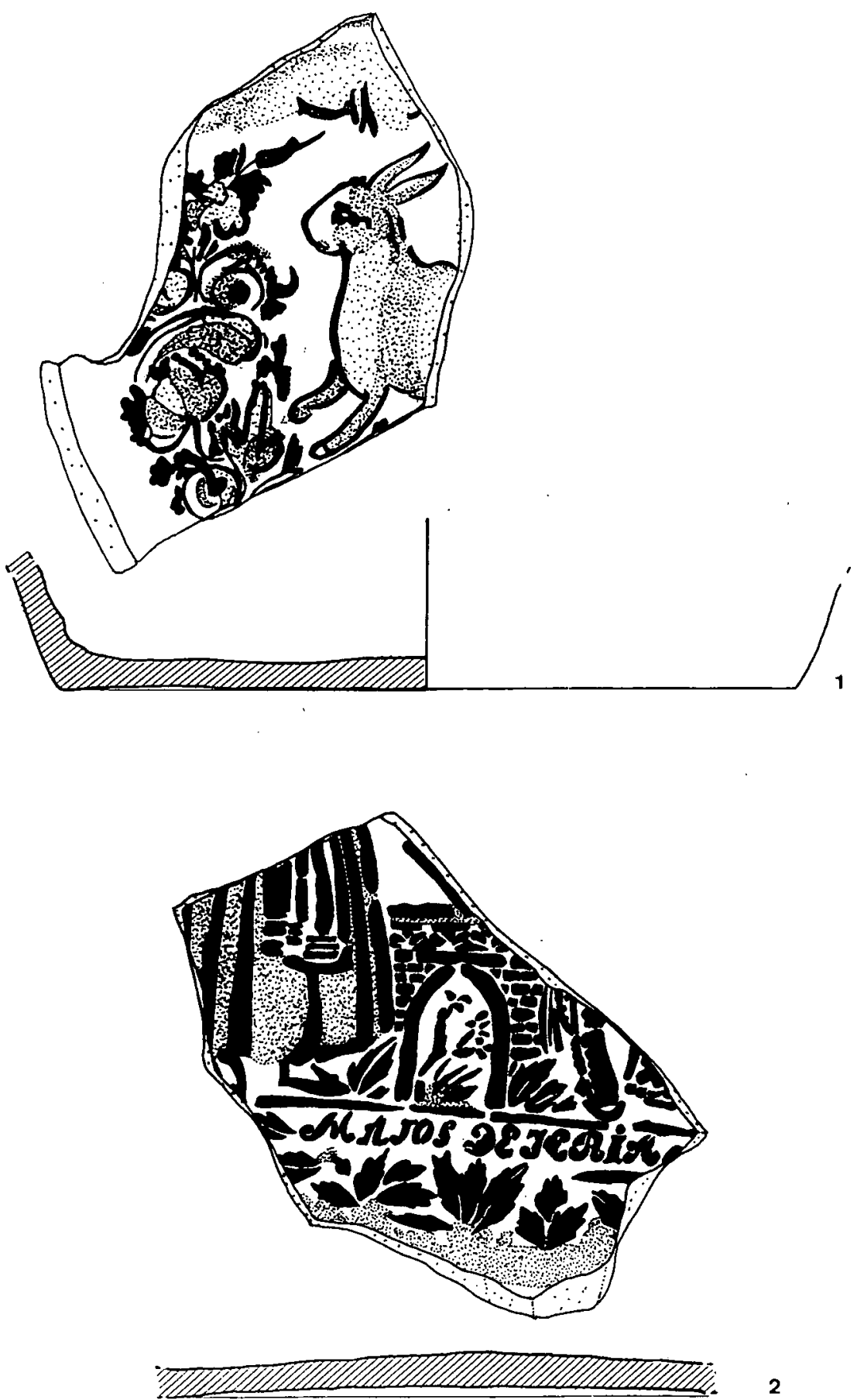

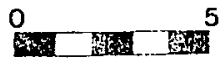

Fig. 12: Usos domésticos: lebrillos (1-2). 